NASA Technical Memorandum 84265

NASA-TM-84265 19820023851

\title{
Mount St. Helens Aerosol Evolution
}

V. R. Oberbeck, N. H. Farlow, W. Fong, K. G. Snetsinger, G. V. Ferry, and D. M. Hayes

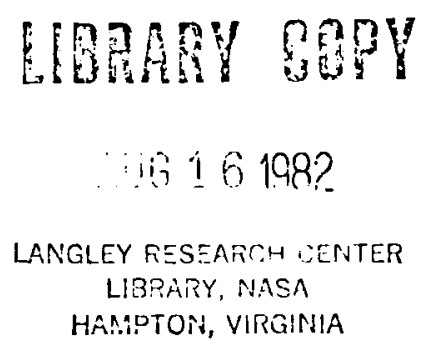





\section{ENTER:}

$\begin{array}{cc} & \text { SELECT } \\ 5 & 1 \\ 5 & \text { SFIFCT }\end{array}$

FN/NASA-TM-84265

SE1OA: TEFM MOT IN DIOTIOHAEY

PNASGA-TM-24295

FIMASA-TH-84266

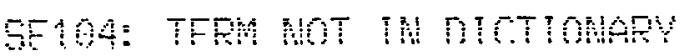

DISPIA $068 \mathrm{~B}$

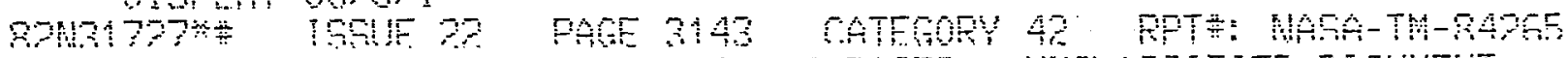

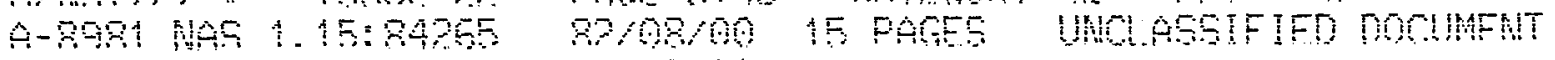

UT! : homt St. Helene Eerosl evolution

AUTH AMPFRFC U.

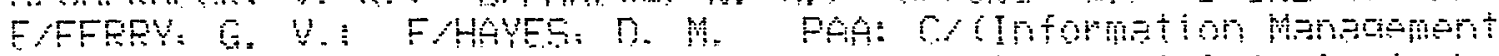

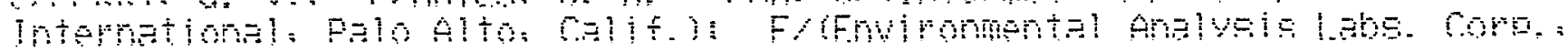
Pichmond Cel t.?

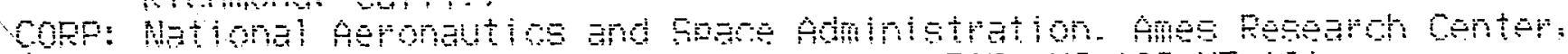

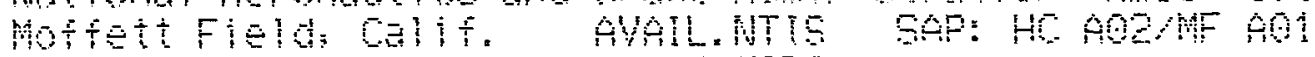

MAS: MEROSOLS STRATOSPHERE WUOLANOES

MINS: ATMOSHERIC COAPOSITOM CLMATE OPTICAL RADAR SAPLING ABA: Autho: 

NASA Technical Memorandum 84265

\section{Mount St. Helens Aerosol Evolution}

V. R. Oberbeck

N. H. Farlow, Ames Research Center, Moffett Field, California

W. Fong, Information Management International, Palo Alto, California

K. G. Snetsinger

G. V. Ferry, Ames Research Center, Moffett Field, California

D. M. Hayes, Environmental Analysis Laboratories Corp., Richmond, California 



\section{MOUNT ST. HELENS AEROSOL EVOLUTION}

V. R. Oberbeck, N. H. Farlow

Atmospheric Experiments Branch, NASA Ames Research Center Moffett Field, California 94035

$$
\text { W. Fong }
$$

Information Management International, Palo Alto, California

K. G. Snetsinger, G. V. Ferry

Atmospheric Experiments Branch, NASA Ames Research Center Moffett Field, California 94035

$$
\text { and }
$$

D. M. Hayes

Environmental Analysis Laboratories Corp., Richmond, California 

Abstract. Stratospheric aerosol samples were collected using a wire impactor during the year following the eruption of Mt. St. Helens. Analysis of samples shows that aerosol volume increased for 6 months due to gas-to-particle conversion and then decreased to background levels in the following 6 months.

\section{Introduction}

During the year following the eruption of Mount St. Helens on May 18, 1980, we obtained samples of aerosols at altitudes of 15.2 and $18.3 \mathrm{~km}$ over California. We used the wire impactor system developed and described by Farlow et a1. [1979]. The method is a direct-impact technique in which aerosols are collected on 3-mil-diameter palladium wires that are deployed directly in the airstream. The statistical and data reduction techniques described in Oberbeck et al. [1981] were used to obtain aerosol concentration size distributions and volume distributions. A major objective of this work was to monitor, at one location $\left(37.5^{\circ}\right.$ latitude and $122^{\circ}$ longitude) and altitude, the stratospheric aerosol population for a period of 1 year to increase our understanding of the long-term effect of a volcanic eruption on the evolution of sulfate aerosols. Injection of aerosols or rapid gas-toparticle conversion increased aerosol mass concentrations soon after the eruption at both 15.2 and $18.3 \mathrm{~km}$, but dispersion reduced concentrations rapidly at both altitudes. However, during the 6 months following the eruption, gasto-particle conversion increased the concentration of large aerosols at $18.3 \mathrm{~km}$, at which time aerosol volume per cubic centimeter of air was about twice the pre-eruption level. Peak aerosol volume decreased to pre-eruption levels by April 1981. Details of the volume distributions are used in this paper to discuss the effects of the eruption on the evolution of aerosols and results are compared with the effects of other volcanic events.

\section{Sampling Procedure}

Lidar observations of changes in stratospheric aerosol levels following the 1974 eruption of Vulcan de Fuego indicate that complex layering developed soon after the eruption, but the aerosol layers soon consolidated to a broad layer centered at about 15-20 km [McCormick, 1978]. Gras and 
Laby [1979] studied changes in aerosols following the 1974 eruption of Vulcan de Fuego using Impactors. They observed that the altitude region from 16-22 $\mathrm{km}$ was high enough to avold variations in aerosol concentration because of the exchange of stratospheric and tropospheric air masses. They concluded that effects of the eruption on stratospheric aerosols would be most readily observed at high altitude. Therefore, because the peak in the stratospheric aerosol layer is normally in this region, we chose $18.3 \mathrm{~km}$ as the altitude for study of the long-term effects of the Mount St. Helens eruption. This appears to be justified; Hoffmann and Rosen [1981] noted that after June 27, 1980, aeroso1 layers between 15 and $20 \mathrm{~km}$ perturbed by the Mount St. Helens eruption merged into the main aerosol layer at $18 \mathrm{~km}$, a condition that persisted through November over Wyoming. Therefore, our $18.3-\mathrm{km}$ aerosol size distributions should be appropriate for assessing the long-term effects of the Mount St. Helens eruption on aerosol growth.

An expected result of volcanic eruptions is conversion of $\mathrm{SO}_{2}$ to $\mathrm{H}_{2} \mathrm{SO}_{4}$ and a coincident increase in the volume of stratospheric aerosols. Therefore, in this paper we present volume distributions which are ideally suited to graphically portraying the integrated aerosol volume in any selected radius interval [Willeke and Whitby, 1975]. This type of distribution effectively reveals aged aerosols in urban aerosol plumes [Whitby, 1980] and in the unperturbed stratosphere [Oberbeck et al., 1981]. It should also effectively document aerosol growth in the months following volcanic eruptions. The method for obtaining aerosol size distributions and volume distributions of pre-impact spherical aerosols from deformed aerosols observed on collection wires has been described by Farlow et al. [1979] and refinements and statistical techniques have been further described by Oberbeck et a1. [1981].

\section{Results and Discussion}

Figure 1 (a) shows the volume distributions observed for aerosols collected at $18.3 \mathrm{~km}$ over California during the period May 1980 to December 2, 1980. In Figure 1 the parameter $\Delta V / \Delta \log \mathrm{R} \mathrm{cm}^{-3}$ is plotted against $R$, the mean particle radius and $\Delta \mathrm{V} / \mathrm{cm}^{-3}$ is the total aerosol volume per cubic centimeter of air in the logarithmic radius interval $\Delta \log R$. Data plotted for May 20 are representative of aerosols before the Mount St. Helens eruption period since 
material did not arrive over California at the $37.5^{\circ}$ latitude, $122^{\circ}$ longitude until mid-June. The plots show a buildup in the aerosol volume until December 2, 1980. The radius of maximum volume concentration increases slightly until December 2, 1980. Also shown in Figure 1 is the total sulfate mass in parts per billion, assuming a $75 \% \mathrm{H}_{2} \mathrm{SO}_{4}$-water solution. At $18.3 \mathrm{~km}$, the sulfate mass doubled between June 25, 1980 (0.74 ppb) and December 2, $1980(1.4 \mathrm{ppb})$.

Figure 1 (b) shows volume distributions for 18.3-km samples collected between December 2, 1980, and April 10,1981. Note that the peak in the December 17 volume distribution is lower than that for December 2, as is the total sulfate mass. The peak volume concentration and the calculated total sulfate mass on April 10, 1981, are below the level of May 20, 1980, indicating that peak aerosol production effects of the eruption declined to background levels by April 1981 .

Figure 2 shows particle concentration data for an altitude of $18.3 \mathrm{~km}$. Between May 20 and December 2, 1980, the concentration of particles with radii larger than $0.15 \mu \mathrm{m}$ increased by a factor of 2 (from $2 / \mathrm{cm}^{3}$ to $4 / \mathrm{cm}^{3}$ ) and then decreased to pre-eruption levels by April 1981 . The trend in concentration of large particles closely follows the trend in aerosol volume, because large particles contribute most to total aerosol volume. Figure 2 shows that at $18.3 \mathrm{~km}$ the concentration of particles with radii less than $0.15 \mu \mathrm{m}$ but larger than $0.06 \mu \mathrm{m}$ decreased after June 25, 1980.

Aerosol volume distributions and concentration at $15.2 \mathrm{~km}$ displayed a markedly different behavior from that observed at $18.3 \mathrm{~km}$. Figure 3 (scales different from Figure 1) shows that the aerosol volume was maximum on June 25, 1980, decreased until october 29, and then increased until April 10, 1981. Figure 4 shows that the concentration of both size fractions increased between May 20 and June 25 at $15.2 \mathrm{~km}$ and then decreased until October 29, 1980. Thereafter, concentration increased until April 10, 1981.

The results shown in Figure $1(\mathrm{~b})$ indicate that the volume of aerosols with radii larger than $0.03 \mu \mathrm{m}$ doubled at $18.3 \mathrm{~km}$ between June 25 and December 2. This increase must be a result either of coagulation of particles with radii smaller than $0.03 \mu \mathrm{m}$, or of gas-to-particle conversion which causes aerosol growth. Transport and concentration of aerosols over California is not a probable explanation, because satellite data show 
transport of the eruption cloud to the north [McCormick, 1981].

Coagulation of particles with radii smaller

than $0.03 \mu \mathrm{m}$ cannot account for the observed doubling of aerosol volume. Rogers et al. [1981] report maximum cloud condensation nuclei (CCN) concentrations of $100 / \mathrm{cm}^{3}$ in scattered debris from the volcanic eruption on June 14, 1980, at $18.6 \mathrm{~km}$. Hofmann and Rosen [1981] report a peak concentration of $500 / \mathrm{cm}^{3}$ at $19.6 \mathrm{~km}$. They report radii of 0.01 to $0.02 \mu \mathrm{m}$ for these particles. If these are peak concentrations for material injected by the eruption or formed rapidly by gasto-particle conversion before June 1980, the materials might have coagulated and increased the volume of the particles larger than $0.03 \mu \mathrm{m}$, which we measured after July 1980. However, there is not sufficient volume in CCN to account for the doubling in volume, so coagulation does not account for the increase in aerosol volume.

Our data show that at $18.3 \mathrm{~km}$ between June 25 and December 2, 1980, the volume of aerosols with radii larger than $0.03 \mu \mathrm{m}$ increased (Figure $1(\mathrm{a})$ ). The concentration of particles with radii less than $0.15 \mu \mathrm{m}$ decreased, and the concentration of particles larger than $0.15 \mu \mathrm{m}$ increased (Figure 2). These data are consistent with the dispersal of an initially high concentration of small particles, accompanied by aerosol growth by condensation upon the small particles, which increased the concentration of large particles.

Our interpretation of gas-to-particle conversion and aerosol growth is consistent with the conclusions reached by other investigators; the volume distributions presented here are complementary to those studies, because the detailed size distribution documents that growth process. Pollack [1981] suggested that early enhanced levels of sulfate coincident with the depletion of $\mathrm{SO}_{2}$ gas and the existence of 100 to $1000 \mathrm{CCN} / \mathrm{cm}^{3}$ at altitudes between $18 \mathrm{~km}$ and $13 \mathrm{~km}$ over Montana and California in June 1980 are evidence of an early phase of rapid gas-to-particle conversion. Rogers [1981] also notes that these high levels of CCN could be due to rapid gas-to-particle conversion or injection. Finally, analysis of SAGE satellite measurements by McCormick [1981] of the effects of aerosol transport and gas-to-particle conversion on optical-depth measurements show that optical depth increased after the eruption. The data show that volcanic material spread north after the eruption, but subsequent enhancement of optical depth above initial levels was interpreted by McCormick to be due to gas-to-particle conversion. 
Some specific comparisons may be made between our data and data of other investigators. Also, the growth of aerosols following the eruption of Mount St. Helens and Vulcan de Fuego can be compared. Our observed factor-of-2 increase in particles with radii greater than $0.15 \mu \mathrm{m}$ is in fair agreement with Hofmann and Rosen [1981], who observed a factor-of-3 increase in particles larger than $0.15 \mu \mathrm{m}$ during the period November 1979 to October 1980. Our California observationthat the increase of aerosol mass with time reached a peak at $18 \mathrm{~km}$ in December-is also in part compatible with Hofmann and Rosen's mass calculation employing log normal fits-to-size data which show that the main aerosol layer over Wyoming stabilized by October 1980 with a peak aerosol mass at $18 \mathrm{~km}$. However, their results show that by December 1980 the main aerosol layer had settled to $16 \mathrm{~km}$. Their results, like ours, indicate that the aerosol layer returned to normal by April 1981.

In general we find that the effects of the Mount St. Helens eruption on the stratospheric aerosol layer were in some ways similar to the effects of the Vulcan de Fuego eruption of 1974. Our finding that aerosol growth occurred at $18.3 \mathrm{~km}$ by gas-to-particle conversion for about 6 months following the eruption is similar to the finding of Gras and Laby [1979]. They observed that in the Southern Hemisphere the mass loading in the altitude range from 16 to $22 \mathrm{~km}$ increased for particles with radii larger than $0.15 \mu \mathrm{m}$ and decreased for particles with radii less than $0.15 \mu \mathrm{m}$. They also found that the decrease in mass of small particles was not sufficient to account for the increase in the mass of large particles. For this reason they believed that although coagulation accounted for their observed decrease in the total concentration of particles, the increase in concentration of larger particles was due to growth by gas-to-particle conversion. We observed the same phenomena and also conclude that gas-to-particle conversion is the mechanism that best explains the data. The data of Hofmann and Rosen [1977] indicate that aerosols in the Northern Hemisphere increased in concentration and reached a peak about 5 months after the eruption of Vulcan de Fuego, whereas Gras and Laby observed a peak aerosol concentration about 7 months after the eruption probably because of delay caused by interhemispheric exchange. Our results, showing a peak about 6-1/2 months after Mount St. Helens erupted, are comparable with the Fuego results.

Aerosol volume and concentration at $15.2 \mathrm{~km}$ over California decreased from June until July 16 , 
1980 (F1gures 3, 4). These results are the same as those of Hofmann and Rosen [1981], who found that material at this altitude over Wyoming was part of the jet stream layer which dispersed after late July over Laramie.

\section{References}

Farlow, N. H., G. V. Ferry, H. Y. Lem, and D. M. Hayes, Latitudinal variations of stratospheric aerosols, J. Geophys. Res., 84, 733-743, 1979.

Gras, J. L., and J. E. Laby, Southern Hemisphere Stratospheric Aerosol Measurements, 2, Time variations and the 1974-1975 aerosol events, J. Geophys. Res., 84, 303-307, 1979.

Ho fmann, D. J., and J. M. Rosen, Balloon observations of the time development of the stratospheric aerosol events of 1974-1975, J. Geophys. Res., 82, 1435-1440, 1977.

Hofmann, D. J., and J. M. Rosen, Balloon-borne observations of stratospheric aerosol and condensation nuclei during the year following the Mount St. Helens eruption, Report No. AP-63, Univ. of Wyoming, Laramie, Wy., 79 pp., 1981.

McCormick, M. P., T. J. Swissler, W. P. Chu, W. H. Fuller, Jr., Post-volcanic stratospheric aerosol decay as measured by lidar, J. Atmos. Sci., 35, 1296-1303, 1978.

Mc Cormick, M. P., Stratospheric aerosols, NASA Tech. Memo 83217, 18 pp., Nov. 1981.

oberbeck, V. R., N. H. Farlow, G. V. Ferry, H. Y. Lem, and D. M. Hayes, A study of stratospheric aerosol maturity, Geophys. Res. Lett., 8 , 18-20, 1981.

Pollack, J. B., Measurements of the volcanic plumes of Mount St. Helens in the stratosphere and troposphere: Introduction, Science 211, $815-816,1981$.

Rogers, E. F., J. G. Hudson, and W. C. Kocmond, Measurements of cloud condensation nuclei in the stratosphere around the plumes of Mount St. Helens, Science 211, 824-825, 1981.

Whitby, $\mathrm{k}$. T., Aerosol formation in urban plumes, in Aerosols: Anthropogenic and Natural, Sources and Transport, edited by T. J. Kneip and P. J. Lioy, Pp. 258-275, Annals of New York Academy of Sci. $338,1980$.

Willeke, K., and K. T. Whitby: Atmospheric aerosols: size distribution interpretation, J. Air Pollution Control Association, 25, 529-534, 1975. 


\section{Figure Captions}

Figure 1. Aerosol volume distributions for samples collected at $18.3 \mathrm{~km}$ over California.

Figure 2. Aerosol particle concentration for aerosols collected at $18.3 \mathrm{~km}$ over California between May 1980 and April 1981.

Figure 3. Aerosol volume distributions for samples collected at $15.2 \mathrm{~km}$ over California during the period June 1980 to April 1981.

Figure 4. Aerosol particle concentration for aerosols collected at $15.2 \mathrm{~km}$ over California during the period May 1980 to April 1981. 
$1 \mathrm{~A}$

-- - 2 DEC 1980, $1.4 \mathrm{ppb} \mathrm{SO}_{4}$ 29 OCT $1980,0.96 \mathrm{ppb} \mathrm{SO}_{4}$

-..- $16 \mathrm{JULY} 1980,0.74 \mathrm{ppb} \mathrm{SO} 4$

25 JUNE 1980, $0.74 \mathrm{ppb} \mathrm{SO}$

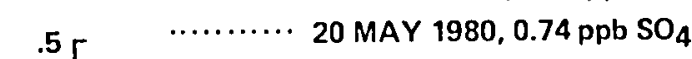

$\infty$

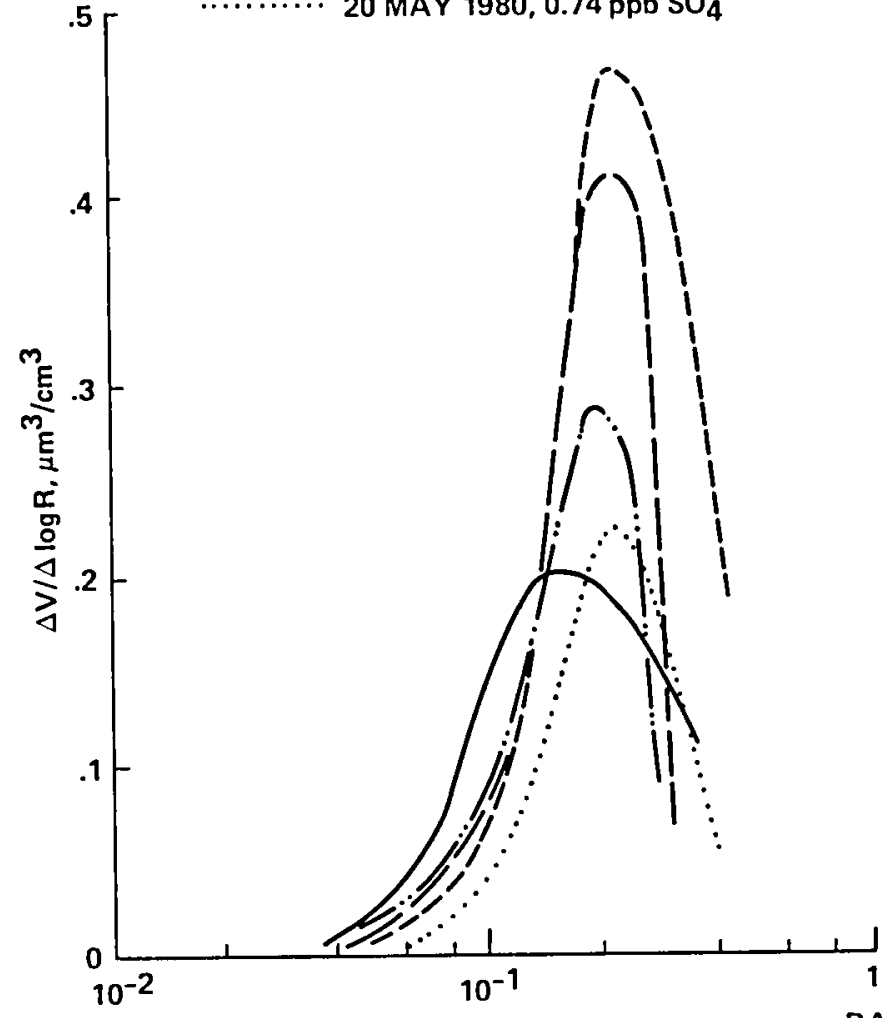

$1 \mathrm{~B}$

- 2 DEC 1980, $1.4 \mathrm{ppb} \mathrm{SO}_{4}$

O 17 DEC 1980, $1.0 \mathrm{ppb} \mathrm{SO}_{4}$

$\square 10$ APRIL 1981, $0.46 \mathrm{ppb} \mathrm{SO}_{4}$

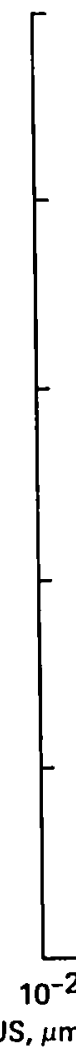

Figure 1

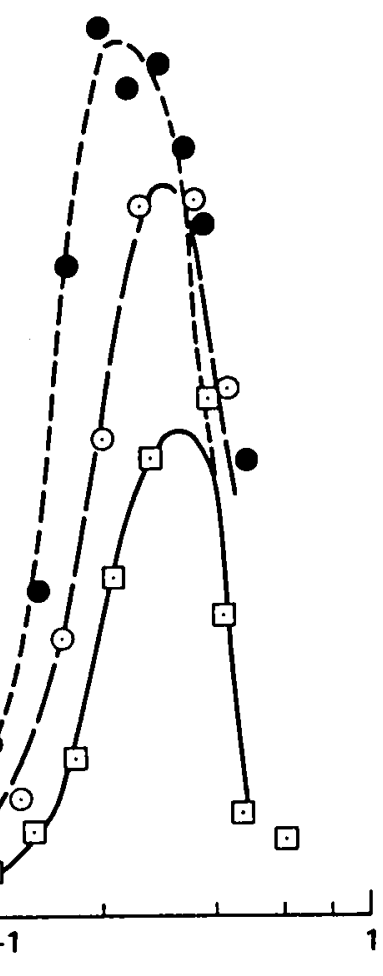

Figure 1 


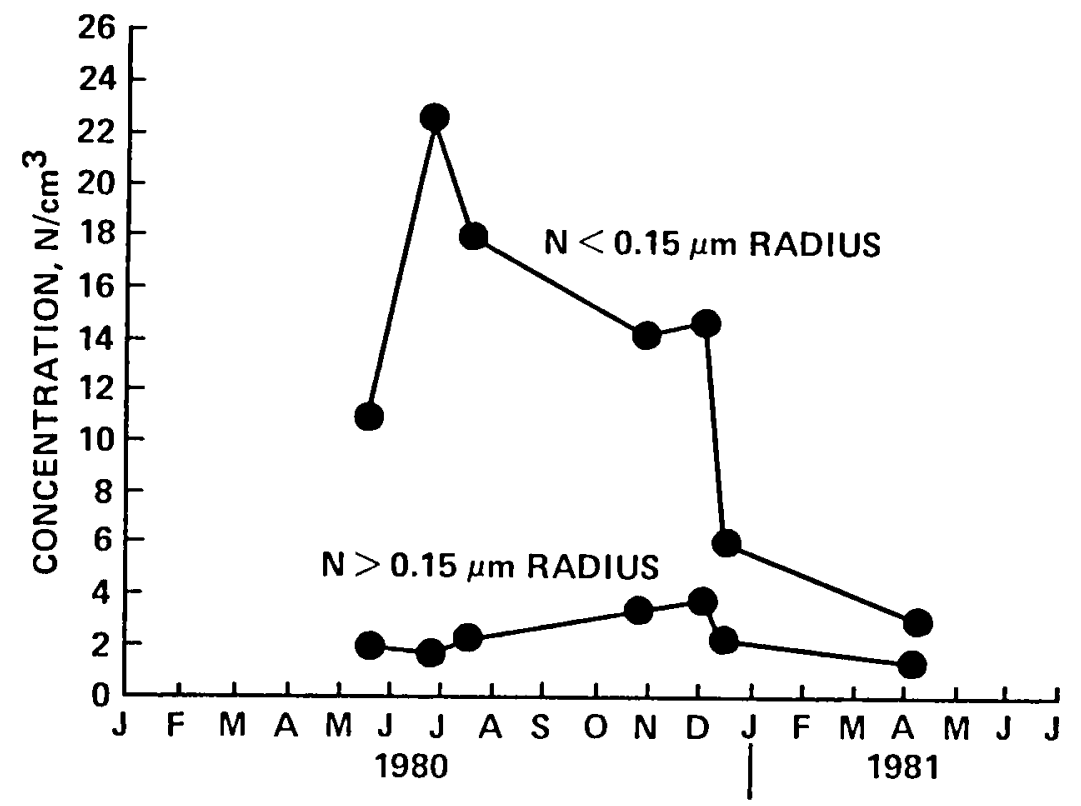

Figure 2 


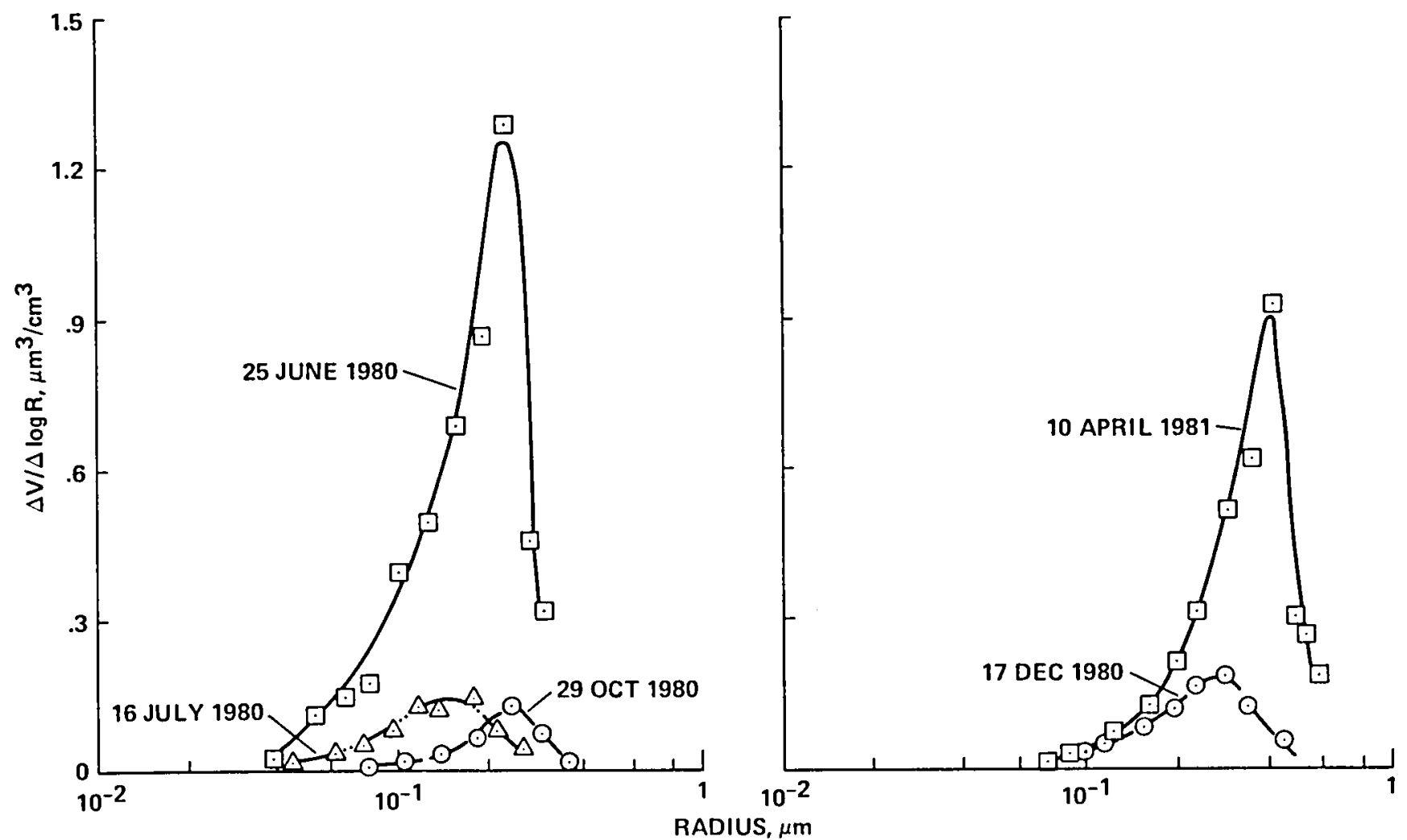

Figure 3 


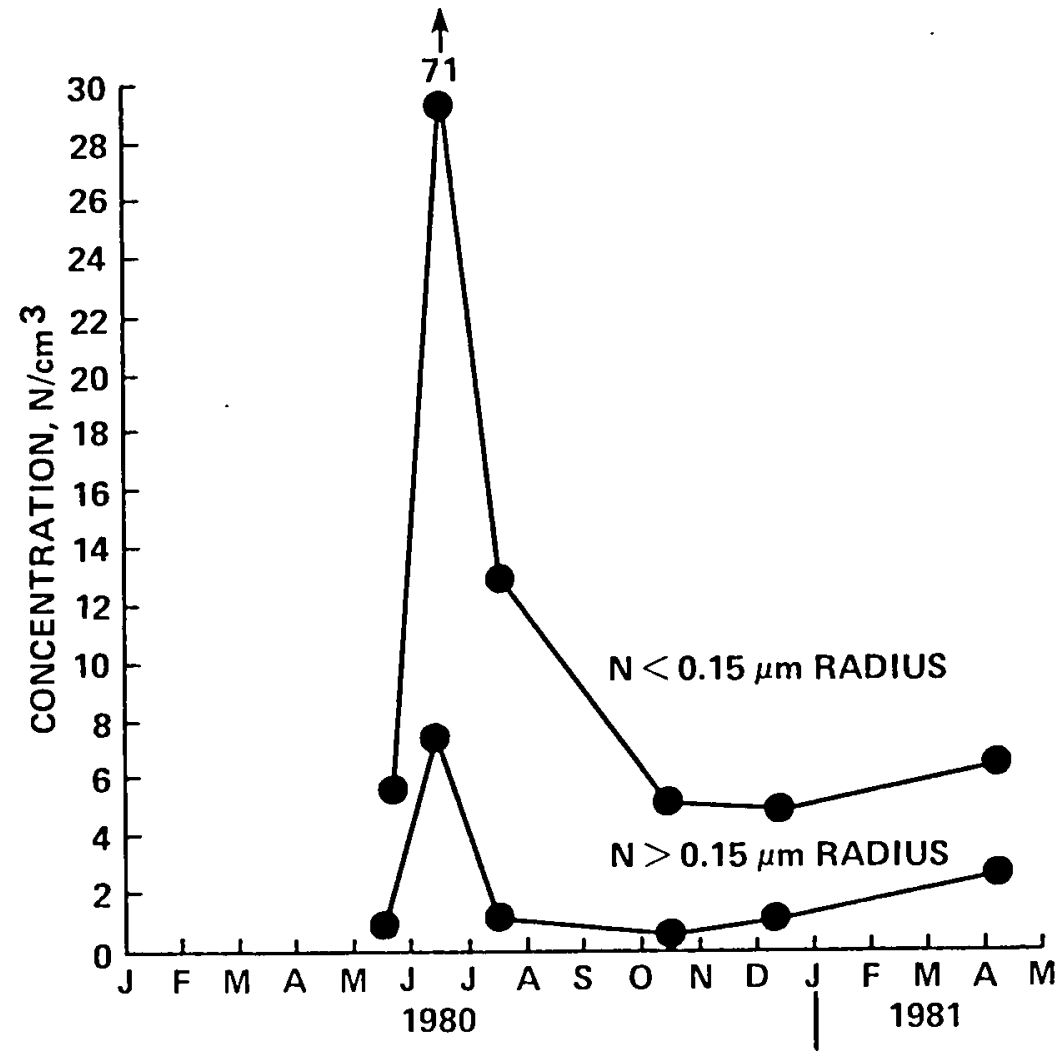

Figure 4 


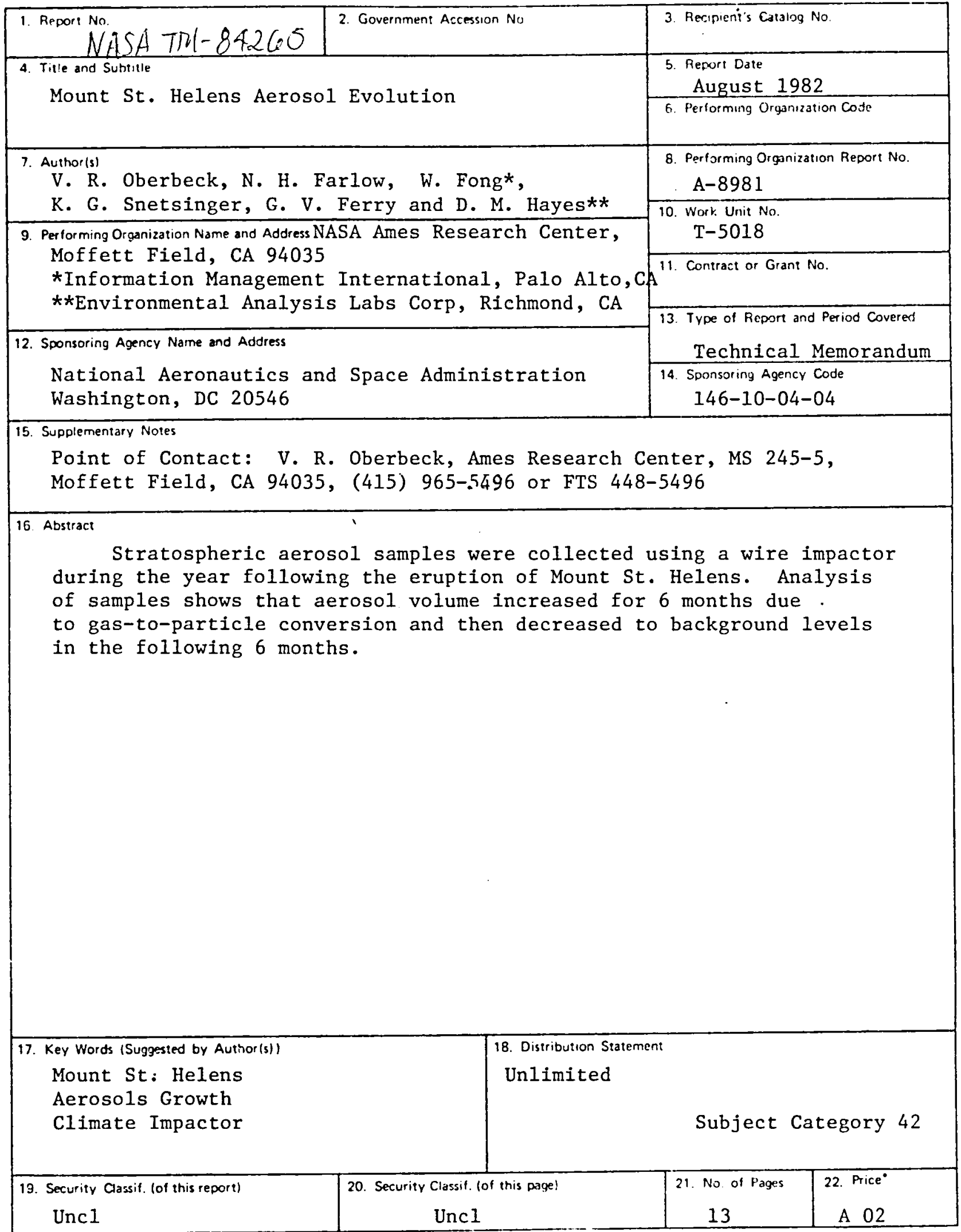




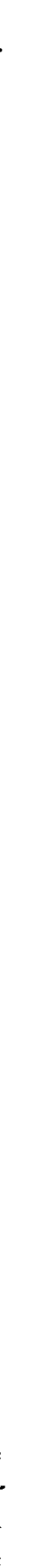


$:$
$:$ 